Conclusion Using RCA methodology to investigate this error identified several deficiencies in the process for immunisation within our Trust enabling action to be taken to ensure that the process is more robust in the future. This has included changing pharmacy purchasing processes for immunisations, identifying both a lead pharmacist and clinician for immunisations, improving links with primary care and PHE and starting to develop minimum standards for immunisations within the Trust. Involving PHE in the RCA process also facilitated learning on a national basis.

\section{SP 07 USING ROOT CAUSE ANALYSIS (RCA) TO ENSURE LEARNING FROM AN ERROR INVOLVING THE NATIONAL INFANT PRIMARY IMMUNISATION SCHEDULE}

Anita Aindow, ${ }^{1}$ Andrea Gill, ${ }^{1}$ David Sharpe, ${ }^{1}$ Catrin Barker, ${ }^{1}$ Joan Mulvoy, ${ }^{1}$ Michelle Falconer, ${ }^{2}$ Andrew Riordan ${ }^{1}$. 'Alder Hey Children's NHS Foundation Trust; ${ }^{2}$ NHS England (Merseyside)

\subsection{6/archdischild-2015-308634.7}

Incident description and consequences In June 2013 the national infant primary immunisation schedule (PIS) for Meningococcal C (MenC) vaccination was changed to the administration of a single dose of MenC vaccine at 3 months of age rather than two doses at 3 and 4 months of age. Information on this change was circulated by Public Health England (PHE) ${ }^{1}$. Only two of the three available branded vaccines were appropriate for this regimen, but this was not identified in our Trust and the pharmacy continued to order and supply Meningitec ${ }^{\circledR}$ vaccine, the one brand that was inappropriate for the new schedule. This error was not detected until April 2014, during which time 37 infants received single dose Meningitec $\AA$ within the Trust.

Purpose A RCA was undertaken to identify the root causes and key learning from this incident and to use this information to reduce the likelihood of future harm to patients. RCA process and methods used:

Gathering information Pharmacy systems were interrogated to identify the affected patients. Information on vaccination status for these children was obtained from Child Health computer systems and the relevant General Practitioners. Representatives from PHE contributed to this information gathering.

Incident Mapping A narrative chronology was developed by the RCA lead and senior Medicines Information Pharmacist prior to the RCA team meeting.

Identification of care and service delivery problems was undertaken by the RCA team during their discussion of the incident.

Identification of contributory factors \& root causes: Contributory factors classification framework was used to aid this process.

Root cause identified The information regarding brand-specific MenC vaccination was not identified when the changes to the immunisation schedule were implemented.

Recommendations from the RCA

To ensure that all patients who may have been affected received their 12 month MenC booster without delay.

To remove Meningitec ${ }^{\circledR}$ vaccine from the Trust and ensure all future prescribing of vaccines is brand-specific.

To identify a lead pharmacist and clinician for immunisation.

To improve links with PHE and primary care immunisation leads.

To implement PHE training and minimum standards for immunisations within the Trust.

\section{REFERENCE}

1 Public Health England/Department of Health/ NHS England letter. Changes to the schedule for meningococcal serogroup C conjugate vaccine. May 2013 https://www. gov.uk/government/uploads/system/uploads/attachment_data/file/197618/MenC_ letter_FINAL.pdf (accessed 30 Jun 2014) 